\title{
Bacillus sporothermodurans, a New Species Producing Highly Heat-Resistant Endospores
}

\author{
BERTIL PETTERSSON,${ }^{1}$ FRITZ LEMBKE, ${ }^{2}$ PHILIPP HAMMER,${ }^{3}$ ERKO STACKEBRANDT, ${ }^{4}$ \\ AND FERGUS G. PRIEST ${ }^{5 *}$ \\ Department of Biochemistry and Biotechnology, Royal Institute of Technology, S-100 44 Stockholm, Sweden ${ }^{1}$; \\ Tetra Pak GmbH, D-70563 Stuttgart, ${ }^{2}$ Institute for Hygiene, Federal Dairy Research Center, D-24103 Kiel, ${ }^{3}$ \\ and DSMZ Deutsche Sammlung von Mikroorganismen und Zellkulturen GmbH, D-38124 \\ Braunschweig, ${ }^{4}$ Germany; and Department of Biological Sciences, Heriot Watt \\ University, Edinburgh EH14 4AS, Scotland, United Kingdom ${ }^{5}$
}

\begin{abstract}
Bacteria that differentiate into highly heat-resistant endospores (HHRS strains) may survive ultrahightemperature treatment of milk and germinate in the final product. They do not noticeably spoil the milk and are nonpathogenic. The complete $(>96 \%)$ 16S rRNA genes from three HHRS strains were identical, and phylogenetic analysis placed them alongside Bacillus firmus in the B. megaterium group of the genus Bacillus. Moreover, the approximately 550 nucleotides between regions U2 and U5 were invariant for seven HHRS strains. However, three cloned 16S rRNA genes from one HHRS strain, M215, showed marked size and sequence variations within the $\mathrm{V} 1$ and $\mathrm{V} 2$ regions. DNA reassociation assays confirmed the distinction between a reference HHRS strain and closely related members of the $B$. megaterium group, notably, $B$. firmus $(30 \%), B$. benzoevorans (28\%), and $B$. circulans (20\%). Ribotyping and pyrolysis mass spectrometry both indicated that the HHRS strains belong to a homogeneous, species-ranked taxon, an exception being strain TP1248, which is slightly atypical. The HHRS strains are unusual in that they grow poorly, if at all, on nutrient agar; good growth is obtained on brain heart infusion agar. On subculture, most HHRS strains form long, filamentous rods which stain unevenly in the Gram reaction. They are strictly aerobic and do not produce acid from sugars. We propose the name Bacillus sporothermodurans for these bacteria, which are phenotypically and phylogenetically distinct from other Bacillus species. The type strain is M215 (= DSMZ 10599).
\end{abstract}

High-temperature processing of milk takes several forms, including autoclaving to produce sterilized milk and ultrahightemperature (UHT) treatment to provide a product which can be stored without refrigeration for prolonged periods, generally, several months. The typical heating regimen for autoclaving is 115 to $120^{\circ} \mathrm{C}$ for 15 to $20 \mathrm{~min}$ or 109 to $115^{\circ} \mathrm{C}$ for 20 to $40 \mathrm{~min}$, and for UHT treatment the range is 135 to $142^{\circ} \mathrm{C}$ for a few seconds, which should result in the destruction of any vegetative cells and endospores present in the raw material. Occasionally, spoilage can occur in sterilized and UHT-treated milk, usually as a result of contamination during filling operations. Members of the genus Bacillus, notably, Bacillus badius, B. cereus, B. licheniformis, B. polymyxa, B. subtilis, and B. stearothermophilus, have been identified in such situations $(10,23$, 36).

In certain circumstances, exceptionally heat-resistant endospores survive the UHT or autoclaving treatment and pass into the final product. These endospores may subsequently germinate and grow in the stored milk $(8,15)$. These mesophilic bacteria, which differentiate into highly heat-resistant spores (HHRS), were detected first in UHT-treated milk from southern Europe in 1985 and in UHT-treated milk from Germany in 1990. Today, the problem is more widespread and has been noted in several other European countries, including the Benelux countries, France, and Spain, as well as in some nonEuropean dairies (15). HHRS bacteria multiply to a maximum of about $10^{5} / \mathrm{ml}$ of milk during storage at $30^{\circ} \mathrm{C}$ for 5 days but generally cause no noticeable spoilage and are nonpathogenic

\footnotetext{
* Corresponding author. Mailing address: Department of Biological Sciences, Heriot Watt University, Edinburgh EH14 4AS, Scotland, United Kingdom. Phone: 441314513464 . Fax: 441314513009. Electronic mail address: F.G.Priest@HW.AC.UK.
}

(15). HHRS bacteria have also been noted in dried milk products.

In this report, we show that the HHRS bacteria which produce these highly temperature-resistant endospores are taxonomically homogeneous and belong to a previously unrecognized species in the genus Bacillus for which we propose the name Bacillus sporothermodurans.

\section{MATERIALS AND METHODS}

Bacterial strains and growth conditions. The HHRS strains used in this study were isolated from UHT-treated milk during 1993. Strains were isolated from products from different dairies (Table 1), with the exception of strains M169 and TP1252, which were isolated from the same dairy but 3 months apart. Reference strains are also listed in Table 1. Working stocks of HHRS bacteria were cultured on brain heart infusion (BHI) agar (Oxoid) or nutrient broth no. 2 (Oxoid) supplemented with $1.5 \%$ agar (Merck) and $1 \mathrm{mg}$ of vitamin $\mathbf{B}_{12}$ (Sigma) per liter at $37^{\circ} \mathrm{C}$ for 2 days, stored at $4^{\circ} \mathrm{C}$, and subcultured every 2 weeks.

rRNA sequence analysis. An isolated colony incubated on BHI agar for $48 \mathrm{~h}$ at $37^{\circ} \mathrm{C}$ was lysed in $10 \mu \mathrm{l}$ of sterile water, and $1 \mu \mathrm{l}$ was used for PCR amplification of the 16S rRNA gene. PCRs were performed with one of the primers biotinylated. Immobilization of the biotinylated PCR products, followed by strand separation and template preparation, was performed with superparamagnetic beads (Dynabeads M-280 Streptavidin; Dynal). The nucleotide sequences of both strands were determined by automated solid-phase DNA sequencing with an ALF DNA Sequencer (Pharmacia) as described previously $(16,24)$. Seven isolates were analyzed in regions U2 to U5 (13), and the virtually complete 16S rRNA gene sequences of three strains were determined. All of the protocols used and details of the primers used have been described elsewhere $(20,24)$.

A PCR product from strain M215 was cloned into $S m a I$-digested $\mathrm{pUC18}$, and the nucleotide sequences of the cloned fragments were determined between regions $\mathrm{U} 1$ and $\mathrm{U} 2$.

All sequences were aligned and edited manually. A secondary structure was created by comparative analysis and used as a guideline in the alignment procedure. Only unambiguously aligned positions, totaling 1,162 nucleotide positions, were used for calculation of similarity matrices. The matrices were corrected by the method of Jukes and Cantor (21), and dendrograms were constructed by the neighbor-joining method (31).

Ribotyping. Chromosomal DNA was prepared from late-exponential-phase cultures (optical density at $600 \mathrm{~nm}$, about 1.0 ) grown in $250 \mathrm{ml}$ of BHI broth at $37^{\circ} \mathrm{C}$ with aeration. Cells were pelleted by centrifugation at room temperature 
TABLE 1. Strains used in this study and their sources

\begin{tabular}{lll}
\hline \multicolumn{1}{c}{ Bacillus species } & \multicolumn{1}{c}{ Strain } & \multicolumn{1}{c}{ Source } \\
\hline B. benzoevorans & DSM 5391 ${ }^{\mathrm{T}}$ & DSMZ \\
B. circulans & DSM 11 & DSMZ \\
B. firmus & DSM 12 & DSMZ \\
B. sphaericus & SO5 012 & CBTBS \\
B. sphaericus & SO5 025 & CBTBS \\
B. sphaericus & SO5 042 & CBTBS \\
B. sphaericus & SO5 148 & CBTBS \\
B. sphaericus & SO5 162 & CBTBS \\
B. sphaericus & SO5 165 & CBTBS \\
B. sporothermodurans & KL3 & UHT-treated milk (Germany) \\
B. sporothermodurans & M169 & UHT-treated milk (Germany) \\
B. sporothermodurans & M172 & UHT-treated milk (Germany) \\
B. sporothermodurans & M215 & UHT-treated milk (Italy) \\
B. sporothermodurans & TP1147 & UHT-treated milk (Germany) \\
B. sporothermodurans & TP1248 & UHT-treated milk (France) \\
B. sporothermodurans & TP1252 & UHT-treated milk (Germany) \\
B. subtilis & 168 & This laboratory \\
B. subtilis & S022 & This laboratory \\
B. subtilis & S315 & This laboratory \\
B. subtilis & S317 & NCIMB 8054 \\
B. subtilis & S322 & This laboratory \\
\hline
\end{tabular}

"DSMZ, German Collection of Microorganisms and Cell Cultures, Braunschweig, Germany.

${ }^{b}$ CBTBS, Collection of Bacillus thuringiensis and Bacillus sphaericus, Institut Pasteur, Paris, France.

NCIMB, National Collection of Industrial and Marine Bacteria, Aberdeen, United Kingdom. Strains from this laboratory are described in reference 29.

and washed in TE buffer (10 mM Tris $\mathrm{HCl}$ [pH 7.5], $1 \mathrm{mM}$ EDTA), and DNA was prepared by phenol extraction as described previously (1). DNA (about 3 $\mu \mathrm{g})$ was digested with EcoRI to completion and electrophoresed in agarose $(0.8 \%)$ in Tris acetate buffer. DNA fragments were transferred to Duralon membranes (Stratagene) essentially as described previously (30) but by using a vacuum blotting device rather than capillary action to effect the transfer. The DNA was fixed by using a UV cross-linker and hybridized to a digoxigeninlabelled 16S rRNA gene probe which had been PCR amplified from $B$. sphaericus DNA in a reaction mixture containing digoxigenin-11-dUTP in placc of dTTP and primers to the extremities of the gene as described previously (2). For visualization of the bound probe, an alkaline phosphatase-linked anti-digoxigenin antibody was used in accordance with the manufacturer's (Boehringer) instructions.

DNA base composition and reassociation. DNA was isolated by chromatography on hydroxyapatite (3), and $\mathrm{G}+\mathrm{C}$ content was determined by high-performance liquid chromatography (34). DNA-DNA hybridization was carried out as described by De Ley et al. (7) with the modifications described by Huss et al. (17) and Escara and Hutton (9), by using a Gilford System 2600 spectrophotometer equipped with a Gilford 2527-R thermal programmer and plotter. Renaturation rates were computed with the TRANSFER.BAS program (18).

Pyrolysis mass spectrometry (Py-MS). Cultures were grown on BHI agar at $37^{\circ} \mathrm{C}$ for 2 days, and a small sample was removed to an iron-nickel alloy foil. The coated foil was dried at $80^{\circ} \mathrm{C}$ for $10 \mathrm{~min}$, loaded onto a Horizon instruments PYMS $200 \times$ pyrolysis system, and pyrolyzed at $530^{\circ} \mathrm{C}$. All strains were analyzed

\section{V1-Region}

B. subtilis M215 Type I M215 Type II M215 Type III

$\begin{array}{llr}67 & \text { GCGGACA-GATGGGAGCTTGCTCCCTGAT--GTTAGC } & 100 \\ 31 & \text { GCGAACTTGATGGGAGCTTGCTCCCTGAGA-GTTAGC } & 66 \\ 31 & \text { GCGAACTTGATGGGAGCTTGCTCCCTGATA-GTTAGC } & 66 \\ 31 \text { GCGAATCTGATGGGAGCTTGCTCCTTTTCAGATTAGC } & 67\end{array}$

\section{V2-Region}

B. subtilis

M215 Type I

M215 Type II

M215 Type III

196 GGT"TCAAACATAAAAGGTGGCTTCG-GCTACCACTTA 232 162 GAAGGAGAATTGAAAGACGGCTTTAAGCTACCACTTA 198 161 GAAGGGGAATTGAAAGATGGCTCCG-GCTATCACTTA 197

FIG. 1. Aligned sequences of three 16S rRNA gene types of HHRS strain M215. Only the nuclcotides within polymorphic regions V1 and V2 are included and compared to the $16 \mathrm{~S}$ rRNA gene of the $m B$ operon of $B$. subtilis (14). Dashes indicate gaps inserted. The underlined nucleotides vary among the three genes. in triplicate, and the results reported are mean values of reproducible patterns. Data were analyzed with GENSTAT software, and clustering was achieved by applying the unweighted pair-group method with arithmetic averages (4).

Phenotypic characterization. Since the milk isolates grew poorly, if at all, on nutrient agar, standard tests for the characterization of Bacillus spp. $(12,29)$ were

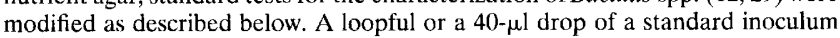
was used which comprised a $5-\mathrm{ml}(0.9 \%)$ saline wash of cells from a BHI agar plate which had been incubated at $37^{\circ} \mathrm{C}$ for 2 days.

Tests were performed as described previously $(12,29)$, but the basal medium was BHI agar rather than nutrient agar, and for casein hydrolysis, $1 \%$ skim milk was used as the substrate. Growth was determined after incubation at $10^{\circ} \mathrm{C}$ for 1 week in a water bath and after 2 days in an air incubator at $50^{\circ} \mathrm{C}$. Utilization of citrate was detected in semisolid BHI agar as described by Gordon et al. (12) for fastidious organisms. The Voges-Proskauer test was conducted in MRVP broth (Oxoid), and reduction of nitrate was determined in BHI broth supplemented with $0.3 \%$ potassium nitrate. Urease activity was determined in Oxoid urea agar base in accordance with the manufacturer's instructions. Acid production from carbohydrates was determined over 14 days by using the standard ammonium salts sugar medium for Bacillus spp. (12). Strains were also examined for acid production from sugars by the method for fastidious strains described by Gordon et al. (12) but by replacing J broth with BHI broth.

API $50 \mathrm{CH}$ trays were inoculated and incubated in accordance with the manufacturer's instructions.

Nucleotide sequence accession numbers. One 16S rRNA sequence from each of the three different types of gene, as discussed below, is available from GenBank under accession number U49078 (type I), U49079 (type II), or U49080 (type III).

\section{RESULTS}

Generic classification. The milk isolates conformed to the phenotypic descriptions of Bacillus spp. in being gram-positive rods which differentiated into oval endospores under aerobic conditions. To provide a more definitive generic allocation, the sequence of almost 1,500 nucleotides, corresponding to more than $96 \%$ of the full 16S rRNA gene, was determined for three typical strains, M215, TP1248, and TP1252. Moreover, the 16S rRNA-encoding gene sequences for about 550 nucleotides between the U2 and U5 regions were invariant for all of the UHT-treated milk strains listed in Table 1, indicating that all HHRS strains are closely related.

Although the direct sequencing procedure resulted in identical nucleotide patterns, we encountered difficulties when determining the base sequences of variable regions V1 and V2 (13) of the 16S rRNA gene. Within these regions, polymorphic

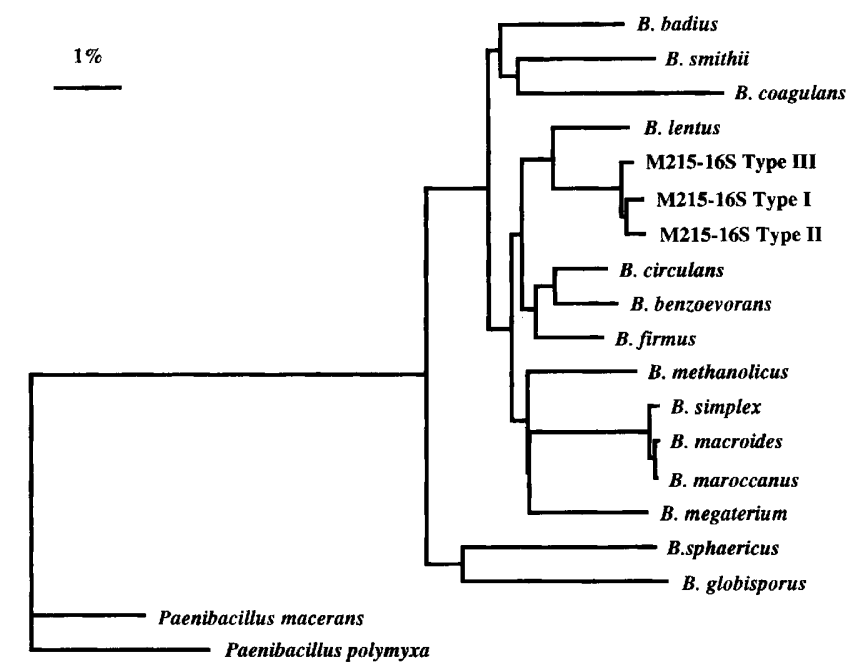

FIG. 2. Unrooted tree of HHRS strain M215 (including the three types of $16 \mathrm{~S}$ rRNA gene) and related Bacillus species with $P$. polymyxa as the outgroup. The scale bar represents a $1 \%$ nucleotide sequence difference as determined by adding all of the horizontal distances connecting two species. 


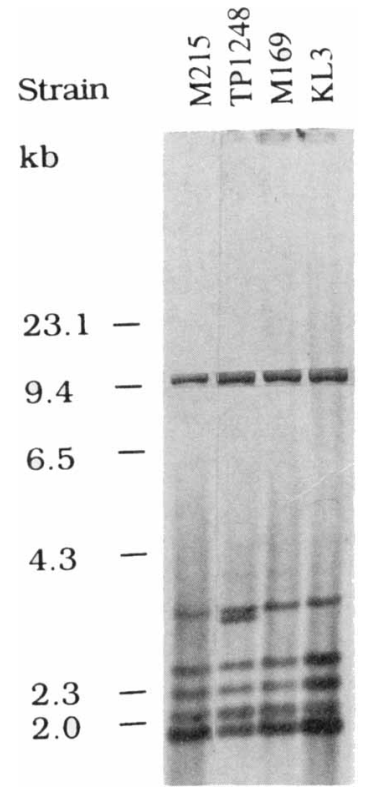

FIG. 3. EcoRI-generated 16S rRNA gene polymorphisms (ribotypes) of representative HHRS strains showing the variation in strain TP1248.

positions (positions with overlapping peaks in the raw data file) indicated the presence of different rRNA genes in the PCR products. Moreover, length variations between strains were noticed in this region. We therefore cloned the PCR product from strain M215 and sequenced several individual clones. We found 16S rRNA genes of three different types among the clones which we labeled types I (1,497 nucleotides long), II (1,496 nucleotides long), and III (1,497 nucleotides long). For correct alignment with the $B$. subtilis sequence (Fig. 1), a gap had to be introduced for the type I and II sequences in the V1 region. Furthermore, the $16 \mathrm{~S}$ rRNA-encoding gene sequence of type I was one nucleotide longer than the type II and III sequences in the V2 region. The underlined positions in Fig. 1 denote sequence differences due to nucleotide substitutions and insertion-deletion points. No polymorphisms were found outside the $\mathrm{V} 1$ and $\mathrm{V} 2$ regions.

Binary similarity values indicated that the HHRS strains were closely related to members of the $B$. megaterium group, e.g., B. lentus ${ }^{\mathrm{T}}$ (T indicates the type strain) (97.6 to $98 \%$ similarity), B. firmus ${ }^{\mathrm{T}}$ (97.3 to $97.5 \%$ similarity), B. benzoevorans ${ }^{\mathrm{T}}$ (96.7 to $97.1 \%$ similarity), and $B$. circulans ${ }^{T}$ (96.7 to $97 \%$ similarity). Sequence similarities to Bacillus reference strains ranged between 93.4 and $97.0 \%$, and those to Paenibacillus species were between 3 and $5 \%$ lower. A dendrogram derived from the dissimilarity values (data not shown) is shown in Fig. 2.

Species classification. DNA reassociation studies revealed low values between the reference HHRS strain (M215) and the type strains of several closely related Bacillus species, notably, $B$. benzoevorans $(28 \%), B$. circulans $(20 \%)$, and $B$. firmus $(30 \%)$, confirming the distinction indicated by the rRNA sequences.

rRNA gene restriction fragment polymorphism determination (ribotyping) provides a powerful means of typing bacteria at the species level and below. EcoRI-generated ribotype patterns (Fig. 3) revealed the HHRS strains to be homogeneous, the only exception to a uniform pattern arising from strain TP1248, which showed two fragments around $3 \mathrm{~kb}$ where other strains had produced a single band only. Ribotype patterns for
HHRS strains M172, TP1147, and TP1252 were identical to that for strain M215 (data not shown). These results confirm the DNA reassociation and rRNA gene sequences in providing strong evidence that the milk isolates should be assigned to a single species.

Further support for a single homogeneous taxon of milk isolates was provided by Py-MS (Fig. 4), in which six of the seven strains formed a single cluster at a high level of relatedness, with strain TP1248 lying on the periphery of the group. We included $B$. sphaericus strains of the same $H$ serotype and some $B$. subtilis strains as outgroups for the Py-MS analysis to indicate the level of clustering achieved by strains within welldefined Bacillus species.

Phenotypic description of milk isolates. The seven HHRS strains were examined with a range of phenotypic tests. The bacteria from $\mathrm{BHI}$ agar plates incubated for 2 days at $37^{\circ} \mathrm{C}$ were rod shaped and measured 3.4 to 5.2 by about $0.7 \mu \mathrm{m}$, but after laboratory cultivation they often formed long, filamentous $(>30-\mu \mathrm{m})$ rods (Fig. 5). They typically reacted unevenly with the Gram stain, producing an unusual, granular appearance rather like a string of beads. The exception was strain TP1248, which produced thin, shorter, evenly stained rods. It should be noted that this filamentous cellular morphology may

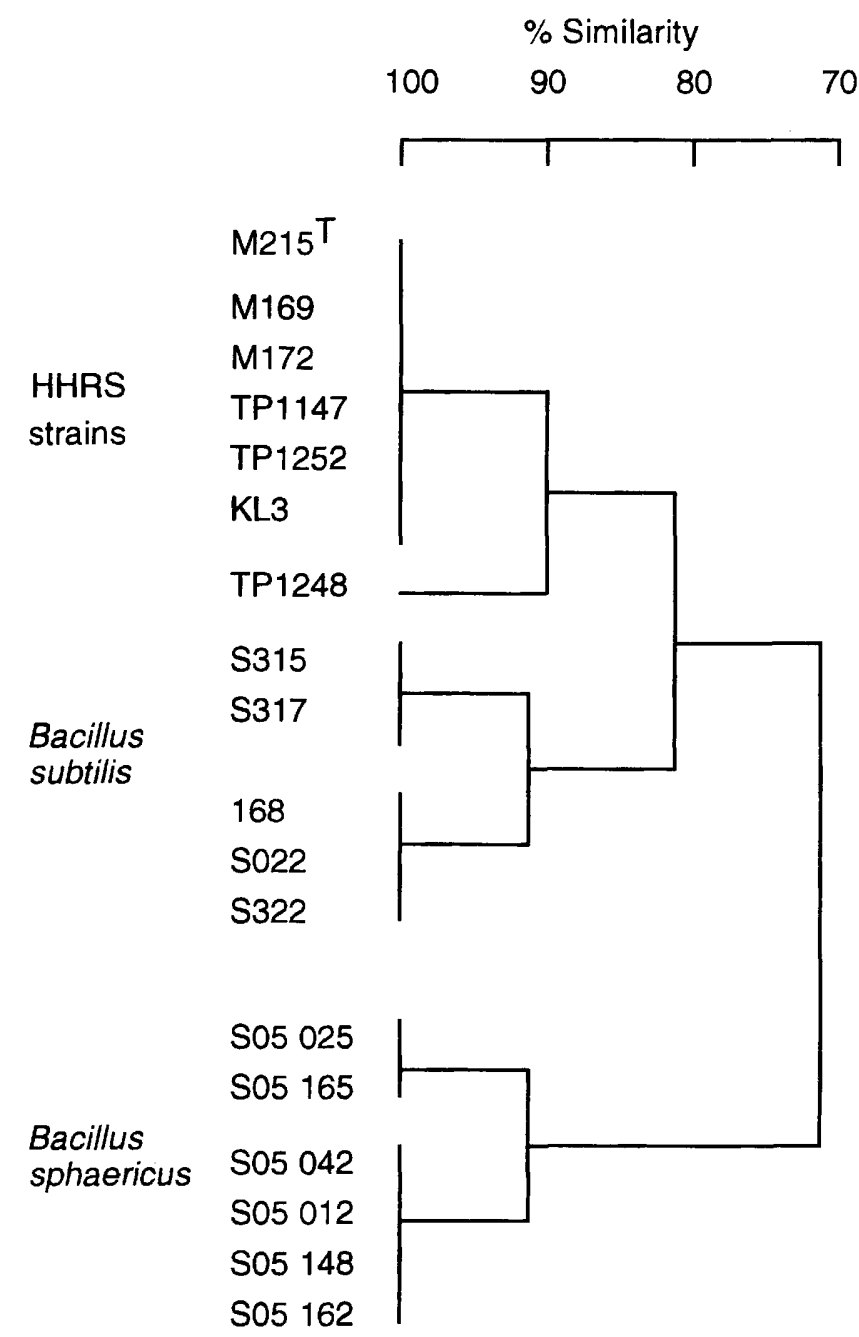

FIG. 4. Dendrogram generated by Py-MS of HHRS strains with $B$. sphaericus serotype $\mathrm{H} 5 \mathrm{a} 5 \mathrm{~b}$ strains and $B$. subtilis strains as outgroups. 
A

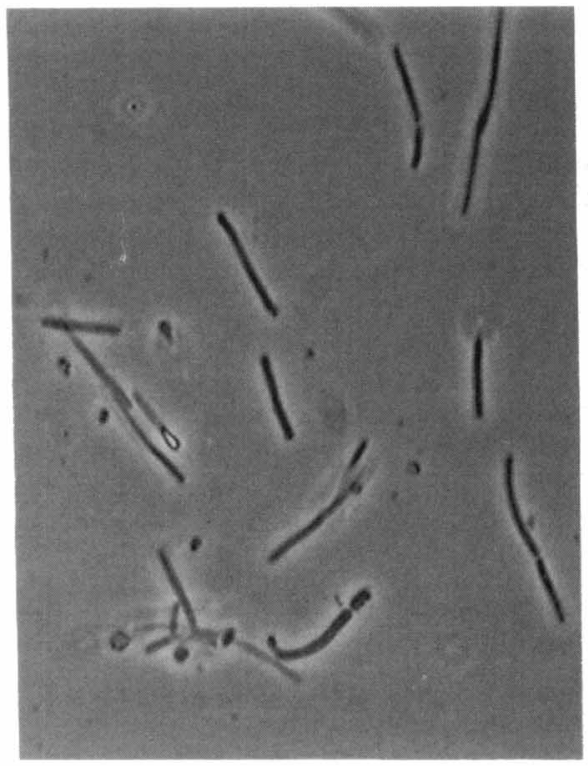

B

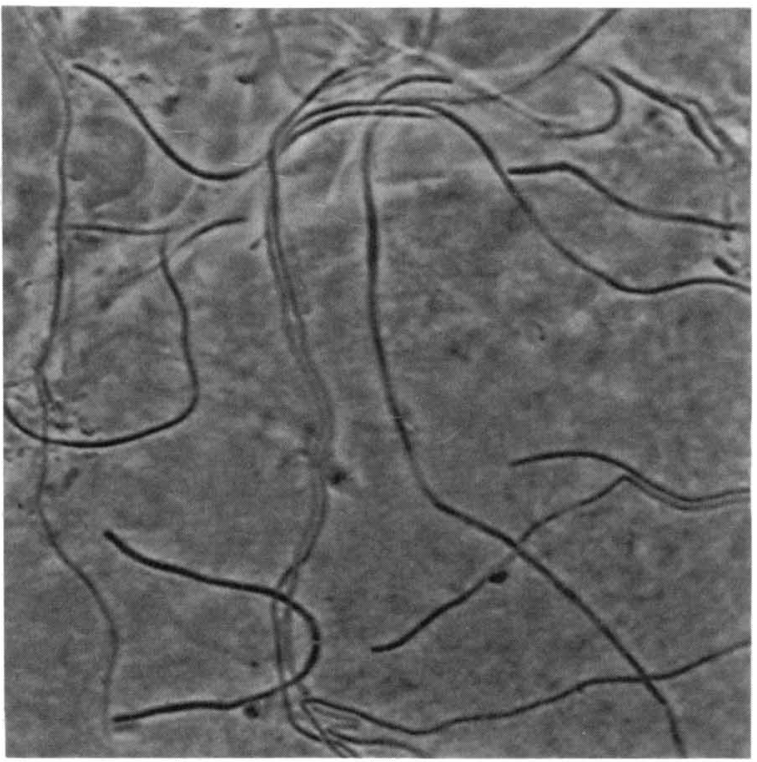

FIG. 5. Phase-contrast micrographs of HHRS strain $\mathbf{M} 215^{\mathrm{T}}$ showing the terminal spore which does not distinctly distend the sporangium (A) and the long, filamentous forms generated following growth on laboratory media (B). Magnification, $\times 1,500$.

be associated with growth on laboratory media, since it was not so evident on primary isolation. All strains were motile. Spores were seen infrequently and were oval (about 1.7 by $0.7 \mu \mathrm{m}$ ) and terminally located without distention of the sporangium. Colonies after growth on $\mathrm{BHI}$ agar at $37^{\circ} \mathrm{C}$ for 2 days were small (about $3 \mathrm{~mm}$ in diameter), smooth, and off-white, but those of strain TP1248 were larger and beige. The milk strains did not grow under anaerobic conditions and gave a negative Voges-Proskauer reaction. They did not produce acid from sugars, including cellobiose, fructose, galactose, glucose, lactose, mannitol, mannose, raffinose, salicin, and xylose, with the standard ammonium salts sugar medium for Bacillus spp. There was, however, weak growth on the surface of the medium, suggesting that limited growth was possible and that the negative reactions were not due to inappropriate medium composition. Indeed, this was checked by examining for acid production from glucose with BHI broth supplemented with glucose and following the procedure for fastidious bacilli described by Gordon et al. (12). Again, a negative reaction was determined. No strains used citrate as a carbon source or hydrolyzed arbutin, arginine, gelatin, or starch, and none grew in $10 \% \mathrm{NaCl}$. No strains used nitrate as a terminal electron acceptor. All strains grew in $2 \% \mathrm{NaCl}$, hydrolyzed esculin, and were positive for the oxidase reaction. Variable test results included growth at 10 and $50^{\circ} \mathrm{C}$, weak hydrolysis of skim milk, urea hydroysis, and growth in $5 \% \mathrm{NaCl}$, as shown in Table 2.

The reactions of strains in API 50CH trays were also examined. The only test which consistently gave a positive reaction was esculin hydrolysis; all other reactions were negative.

The phenotypic reactions of the group of milk isolates are compared in Table 2 with those of phylogenetically related ( $B$. benzeovorans, $B$. firmus, and $B$. lentus) and phenotypically related ( $B$. aneurinolyticus and $B$. badius) species to enable identification of the taxon without recourse to molecular or physical (Py-MS) analyses.

\section{DISCUSSION}

Phylogenetically and phenotypically, the HHRS strains were classified in the genus Bacillus. Their allocation to the B. megaterium branch of the genus by rRNA gene comparisons is consistent with their physiology, since this comprises a group of strains which, like the HHRS strains, are obligate aerobes with little reaction, if any, on sugar substrates in fermentation tests. An exception is $B$. circulans, which is unique in this group in being a facultative anaerobe (29).

An unusual aspect of the rRNA gene sequencing was the discovery of length and sequence variations between the $16 \mathrm{~S}$ rRNA genes within HHRS strains. The significance of the heterogeneity was verified by construction of secondary structures (data not shown). A similar divergence has been found in Mycoplasma mycoides subsp. mycoides type SC, strain PG1, in which a length difference of two nucleotides was detected when the two 16S rRNA genes were compared (25). However, the substantial sequence heterogeneity between the type I, II, and III genes is highly unusual. No variation was observed outside the V1 and V2 regions, unlike the $M$. mycoides variation, which was dispersed throughout the gene (25), but the full picture of sequence heterogeneity will become clearer only when more clones have been analyzed. DNA reassociation studies confirmed that the HHRS strains were different from the type strains of $B$. firmus and $B$. benzoevorans, two of their close phylogenetic partners (Fig. 2).

The HHRS strains are homogeneous in molecular, physical, and phenotypic characteristics, suggesting that they belong to a single species. Ribotyping is a popular method for classifying closely related microorganisms, but the number of different patterns displayed by strains within well-defined species can vary enormously. For example, 43 B. thuringiensis strains have been assigned to 19 ribotypes which largely concur with flagellar serotypes (30), while staphylococci average about 3 ribotype patterns per species (6). Similarly, Listeria species generally contain two or three ribotypes (19). On the other hand, Bru- 
TABLE 2. Phenotypic characteristics of HHRS strains isolated from UHT-treated milk and some related taxa ${ }^{a}$

\begin{tabular}{|c|c|c|c|c|c|c|c|c|c|c|c|c|}
\hline Characteristic & KL3 & M169 & M172 & M215 & TP1147 & TP1248 & TP1252 & B. aneurinolyticus & B. badius & B. benzoevorans & B. firmus & B. lentus \\
\hline \multicolumn{13}{|l|}{ Cytology } \\
\hline Length, $>3 \mu \mathrm{m}$ & + & + & + & + & + & + & + & + & - & + & - & - \\
\hline Filamentous forms ${ }^{b}$ & + & + & + & + & + & - & + & - & - & S & - & - \\
\hline Granular appearance & + & + & + & + & + & - & + & - & - & - & - & - \\
\hline Spores central/terminal & $\mathrm{T}$ & $\mathrm{T}$ & $\mathrm{T}$ & $\mathrm{T}$ & $\mathrm{T}$ & $\mathrm{T}$ & $\mathrm{T}$ & $\mathrm{C}$ & $\mathrm{C}$ & ND & $\mathrm{C}$ & $\mathrm{C}$ \\
\hline Spores bulging & - & - & - & - & - & - & - & + & - & - & - & - \\
\hline \multicolumn{13}{|l|}{ Hydrolysis of: } \\
\hline Esculin & + & + & + & + & + & + & + & - & - & ND & - & + \\
\hline Arbutin & - & - & - & - & - & - & - & - & - & ND & - & + \\
\hline Casein & - & W & W & - & - & - & - & - & + & ND & + & - \\
\hline Gelatin & - & - & - & - & - & - & - & - & + & - & + & - \\
\hline Starch & - & - & - & - & - & - & - & - & - & ND & + & + \\
\hline Urea & - & - & - & - & - & + & - & - & - & + & - & + \\
\hline \multicolumn{13}{|l|}{ Acid from: } \\
\hline Glucose & - & - & - & - & - & - & - & - & - & - & + & + \\
\hline Mannitol & - & - & - & - & - & - & - & - & - & - & + & + \\
\hline Utilization of succinate & - & - & - & - & - & - & - & $\mathrm{V}$ & + & ND & + & - \\
\hline \multicolumn{13}{|l|}{ Growth at: } \\
\hline $10^{\circ} \mathrm{C}$ & - & - & + & + & - & + & ND & ND & ND & ND & ND & + \\
\hline $50^{\circ} \mathrm{C}$ & + & - & - & + & + & + & - & + & V & ND & - & - \\
\hline $5 \% \mathrm{NaCl}$ & - & + & + & - & + & + & - & - & + & ND & + & + \\
\hline $10 \% \mathrm{NaCl}$ & - & - & - & - & - & - & - & - & - & ND & + & - \\
\hline \multicolumn{13}{|l|}{ Miscellaneous } \\
\hline Nitrate reduction & - & - & - & - & - & - & - & + & - & + & + & $\mathrm{V}$ \\
\hline Oxidase & + & + & + & + & + & + & + & + & - & - & - & + \\
\hline
\end{tabular}

${ }^{a}+$, positive reaction; - , negative reaction; $W$, weak reaction; $V$, variable reaction; $T$, terminal; $C$, central; ND, information not known. Data for related species are from references $5,26,27$, and 33 .

$b+$, following growth on laboratory media, cells became very long (over $30 \mu \mathrm{m}$ ) and reacted unevenly with the gram stain to produce characteristic granular cells which appeared like strings of beads; $\mathrm{S}$, sheathed filamentous forms.

cella (35) and Legionella (32) species can be identified by their ribotypes since in these genera ribotype patterns are specific to species. HHRS strains similarly produced a species-specific ribotype pattern, although there was a small discrepancy in the banding pattern of strain TP1248. Ribotyping would therefore be a simple method for unequivocal identification of HHRS strains.

Physical analyses confirmed the homogeneity of the HHRS taxon. The speed and reproducibility of Py-MS and its applicability to a wide range of bacteria make it an attractive tool for epidemiological studies (11). Its application here confirmed the homogeneity of the HHRS strains, indicating that they were no more diverse than strains of serotype H5a5b of $B$. sphaericus and again showed strain TP1248 to be slightly atypical. Nevertheless, the variation was within that demonstrated within a single serotype of $B$. sphaericus and several strains of $B$. subtilis, indicating that this degree of heterogeneity is consistent with the assignment of all HHRS strains to a single species.

Phenotypically, HHRS bacteria are negative for many of the standard tests used in Bacillus taxonomy and identify with $B$. aneurinolyticus and $B$. badius in computerized identification systems based on API (22) and classical phenotypic (28) tests (data not shown). However, they can be distinguished from these phenotypically related taxa and from phylogenetically related taxa by using the information shown in Table 2 . In normal circumstances, HHRS bacteria are unlikely to be confused with other members of the genus Bacillus. They grow poorly, if at all, on standard nutrient agar, although growth is improved by addition of vitamin $\mathrm{B}_{12}$ and additional agar (Merck), which perhaps supplies a mineral requirement. Moreover, their unusual filamentous, almost pleomorphic, cellular morphology (Fig. 5) is different from the normal rodshaped morphology of $B$. firmus and $B$. lentus and the sheathed filamentous forms of $B$. benzoevorans (27). It is possible that strain TP1248 is better adapted to growth on laboratory media than are the other HHRS strains examined here, resulting in rod-shaped cellular morphology and more positive reactions in the phenotypic tests.

HHRS strains are not readily isolated from raw milk, since the normal flora, including B. badius, B. cereus, B. licheniformis, $B$. polymyxa, $B$. subtilis, and B. stearothermophilus strains, rapidly outgrows HHRS strains. Indeed, raw milk must be autoclaved for $5 \mathrm{~min}$ at $121^{\circ} \mathrm{C}$ or heated to $100^{\circ} \mathrm{C}$ for $40 \mathrm{~min}$ to enrich for HHRS spores. It seems likely that the spores contaminate milk at the farm, perhaps originating from feed, and enter the dairy in raw milk, although we cannot conclusively exclude contamination during transportation or in the dairy preprocessing area. Now that these bacteria have been fully described, we hope that further studies will clarify the ecology and environmental distribution of these bacteria.

Description of Bacillus sporothermodurans sp. nov. (Bacillus sporothermodurans (spo. ro. ther. mo. du. r̀ans, Gr. n. sporos, seed, spore; Gr. adj. thermos, warm, hot; L. adj. part. durans, resisting. M. L. adj. part. sporothermodurans, with heat-resisting spores.

Cells from laboratory media are typically long $(>30 \mu \mathrm{m})$, filamentous rods about $0.7 \mu \mathrm{m}$ in diameter which stain un- 
evenly with the Gram reaction to produce a granular or stringof-pearls appearance. Rods 3.4 to $8.2 \mu \mathrm{m}$ long are also seen, especially following primary isolation from milk. Cells are motile by means of peritrichous flagellae. Spores are ellipsoidal, about $1.7 \mu \mathrm{m}$ long, and located terminally and do not distend the sporangium but are rarely seen in normal laboratory culture. Colonies are small, smooth, and off-white to beige. There is no soluble pigment.

Grows poorly, if at all, on nutrient agar; BHI agar is a suitable routine medium.

Strictly aerobic; catalase and oxidase positive.

The Voges-Proskauer reaction is negative, and acid is not produced from a variety of sugars, including cellobiose, fructose, galactose, glucose, lactose, mannitol, mannose, raffinose, salicin, and xylose.

Strains hydrolyze esculin, and most produce weak hydrolysis of casein. Arbutin, arginine, gelatin, starch, and urea (one exception) are not hydrolyzed. Citrate is not utilized as a carbon source. Nitrate is not reduced to nitrite. Growth occurs at 20 to $45^{\circ} \mathrm{C}$, and some strains, including the type strain, are capable of growth at $50^{\circ} \mathrm{C}$. The optimum is around $37^{\circ} \mathrm{C}$.

The $\mathrm{G}+\mathrm{C}$ content of the type strain is $36 \mathrm{~mol} \%$. The type strain is M215, which was isolated from UHT-treated milk and has been deposited in the Deutsche Sammlung von Mikroorganismen und Zellkulturen as strain DSMZ 10599.

\section{ACKNOWLEDGMENTS}

We are grateful to $M$. Goodfellow for provision of facilities and expertise in Py-MS and to J. Burghardt for determination of $\mathrm{G}+\mathrm{C}$ content and DNA-DNA hybridization experiments.

\section{REFERENCES}

1. Aquino de Muro, M., W. J. Mitchell, and F. G. Priest. 1992. Differentiation of mosquito-pathogenic strains of Bacillus sphaericus from non-toxic varieties by ribosomal RNA gene restriction patterns. J. Gen. Microbiol. 138: 1159-1166.

2. Aquino de Muro, M., and F. G. Priest. 1994. A colony hybridization procedure for the identification of mosquitocidal strains of Bacillus sphaericus on isolation plates. J. Invertebr. Pathol. 63:310-313.

3. Cashion, P., M. A. Holder-Franklin, J. McCully, and M. Franklin. 1977. A rapid method for the base ratio determination of bacterial DNA. Anal. Biochem. 81:461-466.

4. Chun, J., E. Atalan, A. C. Ward, and M. Goodfellow. 1993. Artificial neural network analysis of pyrolysis mass spectrophotometric data in the identification of Streptomyces species. FEMS Microbiol. Lett. 107:321-326.

5. Claus, D., and R. C. W. Berkeley. 1986. Genus Bacillus Cohn 1872, p. 1105-1139. In P. H. A. Sneath, N. S. Mair, M. E. Sharpe, and J. G. Holt (ed.), Bergey's manual of systematic bacteriology, vol. 2. The Williams \& Wilkins Co., Baltimore.

6. De Buyser, M. L., A. Morvan, F. Grimont, and N. Elsolh. 1989. Characterization of Staphylococcus species by ribosomal RNA gene restriction patterns. J. Gen. Microbiol. 135:989-999.

7. De Ley, J., H. Cattoir, and A. Reynaerts. 1970. The quantitative measurement of DNA hybridization from renaturation rates. Eur. J. Biochem. 12: 132-142.

8. Duquet, J. P., A. Trouvat, A. Mouniqua, G. Odet, and O. Cerf. 1987. Heat resistant spores in milk used in the manufacture of UHT milk. Lait 67:393.

9. Escara, J. F., and J. R. Hutton. 1980. Thermal stability and renaturation of DNA in dimethylsulphoxide solutions: acceleration of renaturation rates. Biopolymers 19:1315-1327.

10. Foschino, R., A. Galli, and G. Ottogali. 1990. Research on the microflora of UHT milk. Ann. Microbiol. 40:47-59.

11. Goodfellow, M., J. Chun, E. Atalan, and J.-J. Sanglier. 1994. Curie point pyrolysis mass spectrometry and its application to bacterial systematics, $\mathrm{p}$. 87-104. In F. G. Priest, A. Ramos-Cormenzana, and B. Tindall (ed.), Bacterial diversity and systematics. Plenum Press, New York.
12. Gordon, R. E., W. C. Haynes, and C. H.-N. Pang. 1973. The genus Bacillus. Agriculture handbook no. 427. U.S. Department of Agriculture, Washington, D.C.

13. Gray, M. W., D. Sankoff, and R. J. Cedergren. 1984. On the evolutionary descent of organisms and organelles: a global phylogeny based on a highly conserved structural core in small subunit ribosomal RNA. Nucleic Acids Res. 12:5837-5852.

14. Green, C. J., G. C. Stewart, M. A. Hollis, B. S. Vold, and K. F. Bott. 1985. Nucleotide sequence of the Bacillus subtilis ribosomal RNA operon, $m B$. Gene 37:261-266.

15. Hammer, P., F. Lembke, G. Suhren, and W. Heeschen. 1995. Characterization of a heat resistant mesophilic Bacillus species affecting quality of UHTmilk-a preliminary report. Kiel. Milchwirtsch. Forschungsber. 47:303-311.

16. Hultman, T., S. Ståhl, E. Hornes, and M. Uhlén. 1989. Direct solid phase sequencing of genomic and plasmid DNA using magnetic beads as solid support. Nucleic Acids Res. 17:4937-4946.

17. Huss, V. A. R., H. Festl, and K. H. Schleifer. 1983. Studies on the spectrophotometric determination of DNA hybridization from renaturation rates. J. Syst. Appl. Microbiol, 4:184-192.

18. Jahnke, K.-D. 1992. BASIC computer program for evaluation of spectroscopic DNA renaturation data from GILFORD SYSTEM 2600 spectrophotometer on a PC/XT/AT type personal computer. J. Microbiol. Methods 15:61-73.

19. Jaquet, C., S. Aubert, E. N., and J. Rocourt. 1992. Use of rRNA gene restriction patterns for the identification of Listeria species. Syst. Appl. Microbiol. 15:42-46.

20. Johansson, K.-E., B. Pettersson, M. Uhlén, A. Gunnarsson, M. Malmqvist, and E. Olsson. 1995. Identification of the causative agent of granulocytic ehrlichiosis in Swedish dogs and horses by direct solid phase sequencing of PCR products from the $16 \mathrm{~S}$ rRNA gene. Res. Vet. Sci. 58:109-112.

21. Jukes, T. H., and C. R. Cantor. 1969. Evolution of protein molecules, p. 21-132. In H. N. Munro (ed.), Mammalian protein metabolism, vol. 3. Academic Press, Inc., New York.

22. Logan, N. A., and R. C. W. Berkeley. 1984. Identification of Bacillus strains using the API system. J. Gen. Microbiol. 130:1871-1882.

23. Mostert, J. F., H. Luck, and R. A. Hussman. 1979. Isolation, identification and practical properties of Bacillus species from UHT and sterilized milk. S. Afr. J. Dairy Technol. 11:125-131.

24. Pettersson, B., K.-E. Johansson, and M. Uhlén. 1994. Sequence analysis of 16 S rRNA from mycoplasmas by direct solid phase DNA sequencing. Appl. Environ. Microbiol. 60:2456-2461.

25. Pettersson, B., T. Leitner, M. Ronaghi, G. Bolski, M. Uhlén, and K.-E. Johansson. The phylogeny of the Mycoplasma mycoides cluster as determined by sequence analysis of the 16S rRNA genes from the two rRNA operons. J. Bacteriol., in press.

26. Pichonoty, F. 1984. Description de la souche type de Bacillus badius. Ann. Microbiol. (Paris) 135B:21-27.

27. Pichonoty, F., J. Asselineau, and M. Mandel. 1984. Caractérisation biochemique de Bacillus benzoevorans sp. nov., a nouvelle espèce filamenteuse, engainée et mésophile, dégradant divers acides aromatiques et phénols. Ann. Microbiol. (Paris) 135B:209-217.

28. Priest, F. G., and B. Alexander. 1988. A frequency matrix for probabilistic identification of some bacilli. J. Gen. Microbiol. 134:3011-3018.

29. Priest, F. G., M. Goodfellow, and C. Todd. 1988. A numerical classification of the genus Bacillus. J. Gen. Microbiol. 134:1847-1882.

30. Priest, F. G., D. A. Kaji, Y. B. Rosato, and V. P. Canhos. 1994. Characterization of Bacillus thuringiensis and related bacteria by ribosomal RNA gene restriction fragment length polymorphisms. Microbiology 140:1015-1022.

31. Saitou, N., and M. Nei. 1987. The neighbor-joining method: a new method for reconstructing phylogenetic trees. Mol. Biol. Evol, 4:406-425.

32. Saunders, N. A., T. G. Harrison, N. Kachwalla, and A. G. Taylor. 1988. Identification of species of the genus Legionella using a cloned rRNA gene from Legionella pneumophila. J. Gen. Microbiol. 134:2363-2374.

33. Shida, O., H. Takagi, K. Kadowaki, H. Yano, M. Abe, S. Udaka, and K. Komagata. 1994. Bacillus aneurinolyticus sp. nov. Int. J. Syst. Bacteriol. 44:143-150.

34. Tamaoka, J., and K. Komogata. 1984. Determination of DNA base composition by reversed-phase high-performance liquid chromatography. FEMS Microbiol. Lett. 25:125-128.

35. Verger, J. M., F. Grimont, P. A. D. Grimont, and M. Grayon. 1987. Taxonomy of the genus Brucella. Ann. Inst. Pasteur 138:235-238.

36. Westhoff, D. C., and S. L. Dougherty. 1981. Characterization of Bacillus species isolated from spoiled ultrahigh temperature processed milk. J. Dairy Sci. 64:572-580. 